\title{
Syntheses of Poly( $S$-benzyl D- and L-penicillamines) and Their Secondary Structures
}

\author{
Tadao Hayakawa, Yoshiyuki Kondo, Hiroyuki Yamamoto, \\ and Teruo AOE \\ Institute of High Polymer Research, Faculty of Textile Science \\ and Technology, Shinshu University, Ueda, Japan.
}

(Received March 8, 1974)

\begin{abstract}
Poly(S-benzyl D- and L-penicillamines) were prepared from the corresponding $N$-carboxyanhydrides (NCA). These polymers were soluble in alkyl halides, such as chloroform and methylene dichloride, but insoluble in dichloroacetic acid (DCA) and trifluoroacetic acid (TFA). Judging from the results obtained by a study of the infrared absorption (IR) spectra and X-ray photographs, polymers are in the $\omega$-helical structure in the solid state. The results of the optical rotatory dispersion (ORD) and the circular dichroism (CD) in chloroform suggest that these polymers have the $\omega$-helical structure and their helical senses are reversed. By adding TFA to the chloroform solution of these polymers, both ORD and CD curves are markedly changed from the $\omega$-helical structure to the $\beta$-structure. The intrinsic viscosity and the flotation data indicated that the polymer exists in the intermolecular $\beta$-structure in a chloroformTFA mixture.

KEY WORDS Poly(S-benzyl D- and L-penicillamines) / Synthesis / $\omega \rightleftharpoons \beta$ Transition / Infrared Absorption Spectra / X-Ray Diffraction / Optical Rotatory Dispersion / Circular Dichroism /
\end{abstract}

D-Penicillamine ( $\beta, \beta$-dimethyl cysteine) exists in antibiotic penicillin and is an $\alpha$-amino acid with a thiol group in its side chain. It is well established that many synthetic polypeptides form stably the $\alpha$-helical conformation. In the case of poly( $S$-alkyl cysteine), the steric interference between the side chain and main chain makes the $\alpha$-helical conformation unstable. Many kinds of $\operatorname{poly}(S$-alkyl cysteines) have been synthesized and reported to be a $\beta$-structure in the solid state and in solution. ${ }^{1-4}$ Furthermore, Blout $^{5}$ reported that polyamino acids with two groups attached to the same $\beta$-carbon, such as polyvaline and polyisoleucine, do not form the $\alpha$-helix due to the steric factors.

In the present study, we synthesized penicillamine, ${ }^{6}$ which has two branched methyl groups on the $\beta$-carbon of cysteine, and polymerized its $S$-benzyl derivative to $\operatorname{poly}(S$-benzyl D- and L-penicillamines) via the NCA method. The secondary structures of these polymers were studied by means of the ORD, CD, IR, and $\mathrm{X}$-ray techniques in the solid state and in solution.

\section{EXPERIMENTAL}

\section{Materials}

$S$-Benzyl D- and L-Penicillamines. These were synthesized as reported by Crooks. ${ }^{6}$

$S$-Benzyl D-Penicillamine NCA. Dry phosgene was passed through a suspension of $S$-benzyl D-penicillamine $(2.7 \mathrm{~g})$ in $54 \mathrm{ml}$ of dry dioxane for $30 \mathrm{~min}$ at $40^{\circ} \mathrm{C}$. Nitrogen was then passed through the reaction mixture for $30 \mathrm{~min}$. The solvent was removed at $40^{\circ} \mathrm{C}$ under reduced pressure. The residue was treated with $n$ hexane, filtered, and dried. This was recrystallized from ethyl acetate- $n$-hexane; yield, $2.65 \mathrm{~g}$ (88\%); $\mathrm{mp} 163^{\circ} \mathrm{C}$.

Anal. Found: C, 59.07; H, 5.53; N, 5.16\%. Calcd for $\mathrm{C}_{13} \mathrm{H}_{15} \mathrm{NO}_{3} \mathrm{~S}$ :

$$
\text { C, 58.85; H, 5.70; N, 5.28\%. }
$$

$S$-Benzyl L-Penicillamine NCA. S-Benzyl Lpenicillamine NCA was prepared from $S$-benzyl L-penicillamine $(2.0 \mathrm{~g})$ and phosgene in the above mentioned manner; yield, $1.8 \mathrm{~g}$ (81\%); $\mathrm{mp} 163^{\circ} \mathrm{C}$. 
Anal. Found: C, 59.05; H, 5.53; N, 5.06\%. Calcd for $\mathrm{C}_{13} \mathrm{H}_{15} \mathrm{NO}_{3} \mathrm{~S}$ :

C, 58.85; H, 5.70; N, 5.28\%.

Poly(S-benzyl D-penicillamine). S-Benzyl Dpenicillamine NCA $(2.6 \mathrm{~g})$ was dissolved in a chlorobenzene $(4.5 \mathrm{~m} l)$-DMF $(1.5 \mathrm{~m} l)$ mixture and $n$-hexylamine $(0.01 \mathrm{~m} l)$ was added to the solution. The mixture was polymerized at $50^{\circ} \mathrm{C}$ for two days and yielded a semisolid gel. The polymer was washed successively with ether, methanol, water, and acetone, and dried; yield, $2.1 \mathrm{~g}(97 \%)$.

Anal. Found: C, 64.91; H, 6.51; N, 6.27\%. Calcd for $\left(\mathrm{C}_{12} \mathrm{H}_{15} \mathrm{NOS}\right)_{n}$ :

C, 65.12; H, 6.38; N, 6.33\%.

$N$-Terminal titration, $\mathrm{MW}=16000(\mathrm{DP}=72)$.

Poly(S-benzyl L-penicillamine). S-Benzyl Lpenicillamine NCA $(1.3 \mathrm{~g})$ was polymerized in the same way as mentioned above; yield, $0.90 \mathrm{~g}$ $(83 \%)$.

Anal. Found: C, 65.42; H, 6.68; N, 6.35\%. Calcd for $\left(\mathrm{C}_{12} \mathrm{H}_{15} \mathrm{NOS}\right)_{n}$ :

C, 65.12; H, 6.38; N, 6.33\%. $N$-Terminal titration, $\mathrm{MW}=15700(\mathrm{DP}=71)$.

\section{Methods}

Optical rotatory dispersion (ORD), circular dichroism (CD) and infrared absorption (IR) spectra measurements were made on the ORD/UV-5 instrument with a CD attachment and the IR DS-301 instrument, respectively, both made by the Japan Spectroscopic Co., Ltd. The ORD and CD were measured with $0.1-$ $10-\mathrm{mm}$ cells for the $210-600-\mathrm{nm}$ wavelengths. As for $C D$, the measured values of $\varepsilon_{L}-\varepsilon_{R}$ were converted to molar ellipticity. The concentration of the samples were in the $0.1-1.0-\%$ range. The $\mathrm{X}$-ray diffraction photographs were taken with a Rigakudenki Geigerflex, using a $\mathrm{Cu}$-target. The intrinsic viscosity was measured in an Ubbelohde-type viscometer at $20^{\circ} \mathrm{C}$. The measurement of the flotation coefficient was made in a Hitachi Model UCA-1A ultracentrifuge at $22^{\circ} \mathrm{C}$. The rotor speed used was $51200 \mathrm{rpm}$.

\section{RESULTS AND DISCUSSION}

\section{Conformation of the Polymers in the Solid State}

IR Studies and X-Ray Analyses. The IR spectra of the films of $D$ - and L-polymers cast from the chloroform solution are shown in

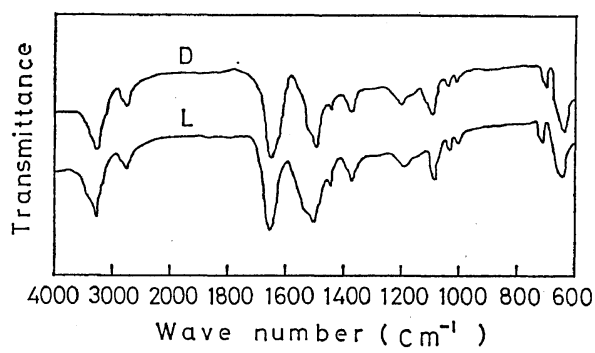

Figure 1. Infrared spectra of $\operatorname{poly}(S$-benzyl D- and L-penicillamines) in solid films.

Table I. Characteristic absorption bands of poly( $S$-benzyl D- and L-penicillamines) in solid film

\begin{tabular}{lcc}
\hline \multirow{2}{*}{ Assignment } & \multicolumn{2}{c}{ Wave number, $\mathrm{cm}^{-1}$} \\
\cline { 2 - 3 } & D-Polymer & L-Polymer \\
\hline Amide A & $3370(\mathrm{vs})^{\mathrm{a}}$ & $3365(\mathrm{vs})$ \\
Amide B & $3037(\mathrm{w})$ & $3035(\mathrm{w})$ \\
Amide I & $1660(\mathrm{vs})$ & $1658(\mathrm{vs})$ \\
Amide II & $1545(\mathrm{sh})$ & $1545(\mathrm{sh})$ \\
\hline
\end{tabular}

a vs, very strong; w, weak; sh, shoulder.

Figure 1. The wave numbers of the characteristic amide bands are listed in Table I. Both the D- and L-polymers gave almost the same IR spectra. The amide I and amide II are found at 1660 and $1545 \mathrm{~cm}^{-1}$. The absorption shoulder at $1545 \mathrm{~cm}^{-1}$ may be due to the influence of the absorption of the $S$-benzyl group. This suggests the polymers do not form the $\beta$-conformation. The IR dichroism of the stretched film of poly( $S$-benzyl D-penicillamine) is shown in Figure 2. This shows that the direction of the $>\mathrm{C}=\mathrm{O}---\mathrm{H}-\mathrm{N}<$ in the polypeptide is the same

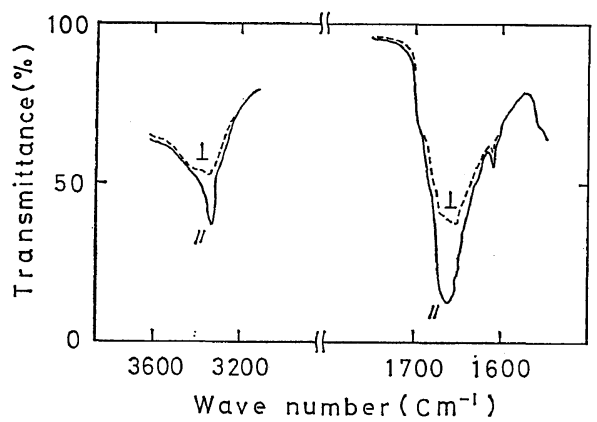

Figure 2. Infrared dichroism of stretched film of poly $(S$-benzyl D-penicillamine).

Polymer J., Vol. 6, No. 6, 1974 
Table II. Spacings in X-ray diffraction patterns of poly( $S$-benzyl D- and L-penicillamines) in solid film

\begin{tabular}{ccccccc}
\hline \multirow{2}{*}{ Order } & \multicolumn{2}{c}{$\mathrm{D}-$ Polymer } & & \multicolumn{2}{c}{ L-Polymer } \\
\cline { 2 - 3 } \cline { 5 - 6 } & $d, \AA$ & Intensity & & \multicolumn{2}{c}{$d, \AA$} & Intensity $^{\mathrm{a}}$ \\
\hline $\mathbf{R}_{1}$ & 13.3 & $\mathrm{vs}$ & & 13.3 & vs \\
$\mathbf{R}_{2}$ & 5.10 & vs & & 5.15 & vs \\
$\mathbf{R}_{3}$ & 4.02 & w & & 4.02 & w \\
$\mathbf{R}_{4}$ & 3.27 & w & & 3.30 & w \\
\hline
\end{tabular}

a vs, very strong; w, weak.

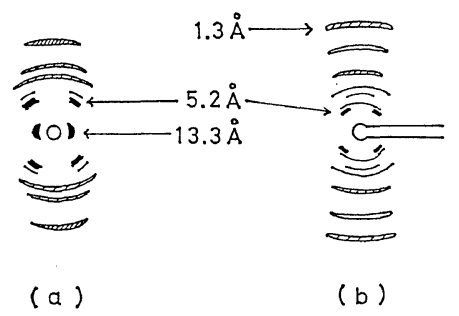

Figure 3. Schematic X-ray diffraction pattern of stretched films of poly( $S$-benzyl D-penicillamine): (a), 3.9-cm flat camera, X-ray normal to fibre axis; (b), $2.87-\mathrm{cm}$ cylindrical camera, X-ray normal to fibre axis which is along camera axis.

as that of the orientation and suggests the formation of an intramolecular hydrogen-bonded helical structure similar to the $\alpha$-helix. ${ }^{7}$

The observed spacings and intensities obtained from the X-ray diffraction patterns in the films of D- and L-polymers are listed in Table II. These results suggest both of them take the same secondary structure. Figure 3 shows the schematic X-ray diffraction pattern of an oriented poly( $S$-benzyl D-penicillamine) film. The strong spacing at about $13.3 \AA$, which lies along the equatorial arc, shows that the spacing corresponds to the helix-helix interval of the $\alpha$-helical polypeptide (a). ${ }^{8}$ The layer reflection observed at $5.2 \AA$ (a). Figure 3 -b shows a meridional reflection corresponding to a spacing of about $1.3 \AA$, and suggests that the structure is based on the $\omega$-helical structure like $\omega$-poly$(\beta \text {-benzyl L-aspartate })^{9-11}$ and poly $(S$-benzylthio L-cysteine). ${ }^{9}$ The conformation of poly( $S$-benzyl $D-$ and L-penicillamines) differs from the $\beta$ structure of poly ( $S$-methyl cysteine) and poly( $S$-benzyl cysteine). ${ }^{12,13}$
The solid state structures of poly $(S$-benzyl Dand L-penicillamines) estimated from IR and $\mathrm{X}$-ray analyses are considered to be the $\omega$ structure.

\section{Conformation of the Polymers in Solution}

Optical Rotatory Dispersion and Circular Dichroism. The ORD curves of poly( $S$-benzyl D-penicillamine) for the $300-600-\mathrm{nm}$ wavelengths in a chloroform-TFA mixture are shown in Figure 4. In 100-\% chloroform (curve A), the dextrorotation increases with decreasing wavelength. When $1 \%$ of TFA is added to this chloroform solution (curve B),

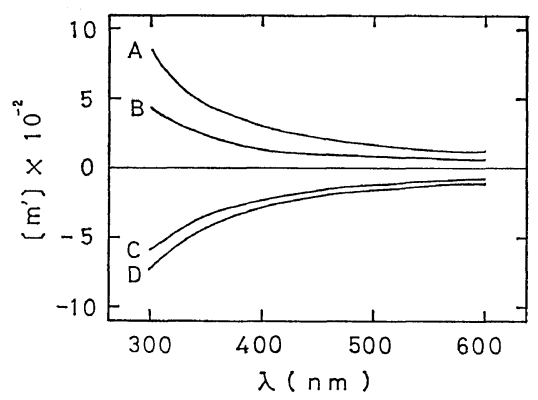

Figure 4. ORD of $\operatorname{poly}(S$-benzyl D-penicillamine) in a chloroform-TFA mixture as a function of solvent composition at $22^{\circ} \mathrm{C}$ : volume $\%$ of TFA, A, 0; B, 1; C, 2; D, 5 .

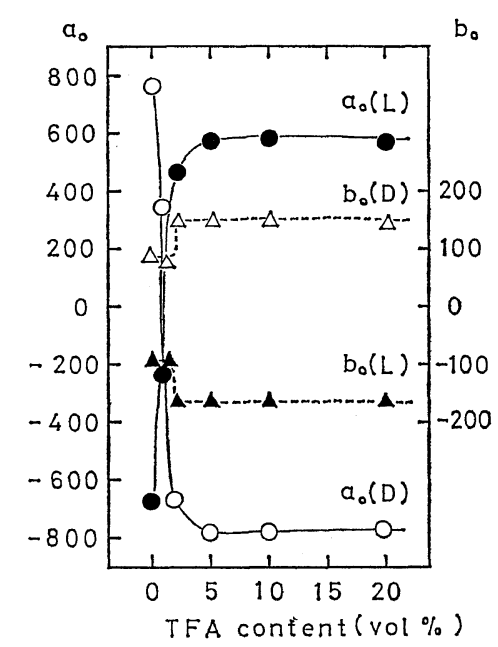

Figure 5. Dependence of the $a_{0}$ and $b_{0}$ of poly( $S$-benzyl D- and L-penicillamines) in a chloroformTFA mixture of solvent composition at $22^{\circ} \mathrm{C}$ : (O) $a_{0}(\mathrm{D}) ;(\mathbf{O}) a_{0}(\mathrm{~L}) ;(\triangle) b_{0}(\mathrm{D}) ;(\mathbf{\Lambda}) b_{0}(\mathrm{~L})$. 
the rotation decreases. 2\% of TFA (curve C) inverts the rotation into levo. This means that a small amount of TFA causes a drastic conformational transition. The values of the parameters, $a_{0}$ and $b_{0}$, derived from the MoffittYang equation, were determined from the ORD curves for the 350-600-nm wavelengths and are shown in Figure 5. As seen in Figure 5, both the D- and L-polymers gave almost the same behavior. 2-3\% of TFA causes the marked changes in $a_{0}$. The $a_{0}$ value changed from +760 to -790 in the D-polymer and from -680 to +590 in the L-polymer. These results differ from the $\alpha$-helix to random coil transition of the usual $\alpha$-helical polypeptides ${ }^{14}$ owing to the absorption of $S$-benzyl group.

In order to clarify the conformation in solution, ORD and CD measurements were carried out in the ultraviolet region. Figure 6 shows the ORD curves of poly $(S$-benzyl D- and Lpenicillamines) in chloroform. $\operatorname{Poly}(S$-benzyl D-penicillamine) exhibits a peak at $248 \mathrm{~nm}$ with $\left[\mathrm{m}^{\prime}\right]_{248}=+2900 \mathrm{deg} \mathrm{cm} / \mathrm{dm}$, a crossover point near $233 \mathrm{~nm}$, a trough at $228 \mathrm{~nm}$ with $\left[\mathrm{m}^{\prime}\right]_{228}=$

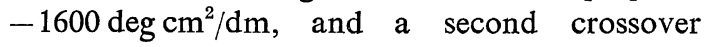
point near $222 \mathrm{~nm}$, and a peak can be expected below $220 \mathrm{~nm}$. Furthermore, the ORD shows two small aromatic (benzyl group) Cotton effects in the 273- and 265-nm regions.

The $C D$ curves are shown in Figure 7. The ORD and the CD srectra correspond well to

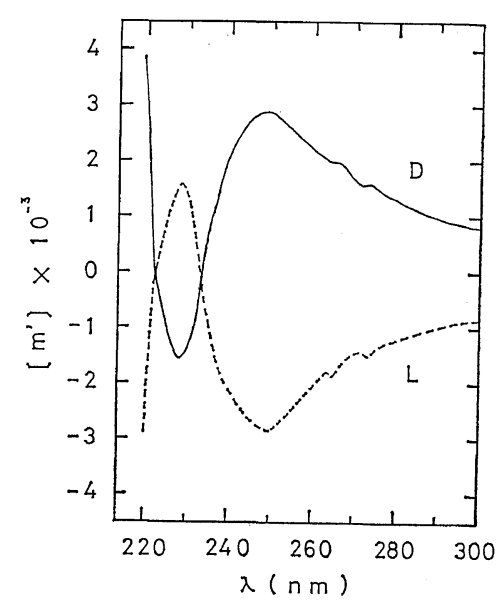

Figure 6. ORD of $\operatorname{poly}(S$-benzyl D- and L-penicillamines) in chloroform at $22^{\circ} \mathrm{C}$.

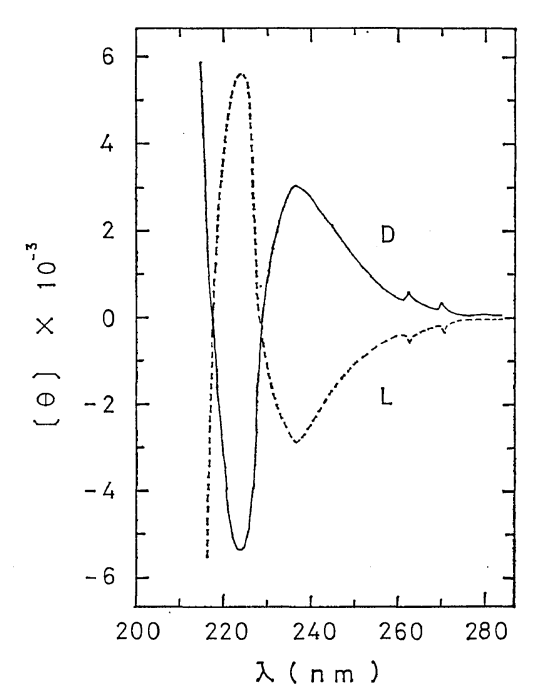

Figure 7. CD of poly( $S$-benzyl D- and L-penicillamines) in chloroform at $22^{\circ} \mathrm{C}$.

each other. Two dichroism bands at 236 and $223 \mathrm{~nm}$, with $[\theta]_{236}=+3000$ and $[\theta]_{223}=-5400$ were observed for D-polymer, and a positive dichroism band below $220 \mathrm{~nm}$ can be expected. The ORD and the CD curves of the L-polymer are found in the same positions and have the same magnitudes with an opposite sign. The positive ellipticity band at $236 \mathrm{~nm}$ appears to be the $\pi-\pi^{*}$ transition of the $S$-benzyl group and the negative band at $223 \mathrm{~nm}$ is to be assigned to the $n-\pi^{*}$ peptide electronic transition. In comparison with the usual polypeptides, this $n-\pi^{*}$ peptide electronic transition shows that $\beta$, $\beta$-dimethyl groups in the side chain reverse the conformational screw sense of this polypeptide. As in the case of the left-handed $\alpha$ helical poly( $\beta$-benzyl L-aspartate), ${ }^{15-17}$ we may consider that L-polymer takes a left-handed sense and D-polymer does a right-handed one. The ellipticity band at $236 \mathrm{~nm}$ associated with the absorption bands of the aromatic group is close to $\operatorname{poly}\left(N^{\omega}\right.$-carbobenzoxy L- $p$-aminophenylalanine $)^{18}$ and $\operatorname{poly}\left(N^{\omega, \omega^{\prime}}\right.$-dicarbobenzoxy Larginine), ${ }^{19}$ in which the helical arrangements in solution delineate the stacking of the aromatic Cotton effect. The band at $223 \mathrm{~nm}$ seems close to the $n-\pi^{*}$ transition observed in the usual $\alpha$-helical polypeptide, but the magnitude is much smaller. 


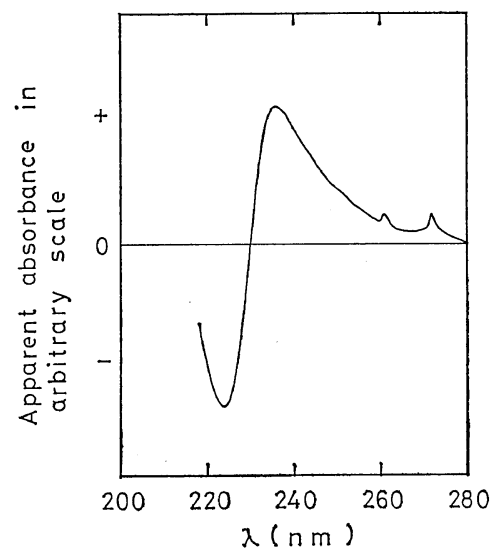

Figure 8. CD of a solid film of poly $(S$-benzyl Dpenicillamine).

The CD spectrum of the film of $\operatorname{poly}(S$ benzyl D-penicillamine) cast from the chloroform solution is shown in Figure 8. The positions of the CD curve of the film are very similar to that of the polypeptide in chloroform. Supposing that the solid conformation of the polypeptide is maintained in solution, this suggests that the polypeptide has an $\omega$-structure in chloroform solution. From these results we consider that $\operatorname{poly}(S$-benzyl D-penicillamine $)$ forms a right-handed $\omega$-helical structure and $\operatorname{poly}(S$-benzyl L-penicillamine) forms a left-

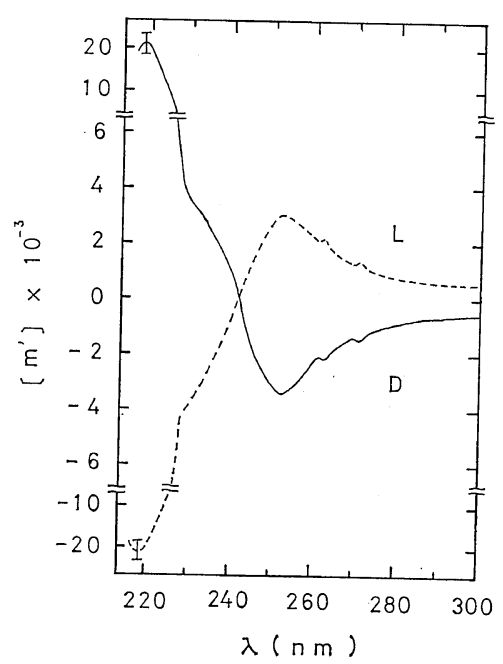

Figure 9. ORD of poly(S-benzyl D- and L-penicillamines) in a $95-\%$ chloroform - 5-\% TFA mixture at $22^{\circ} \mathrm{C}$.

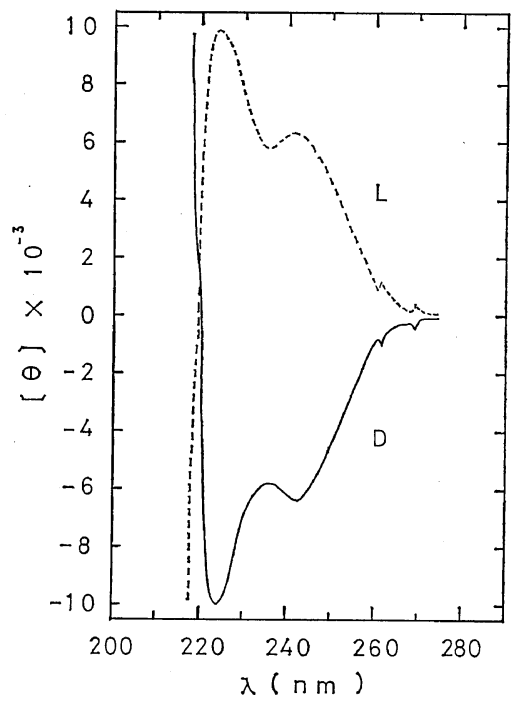

Figure 10. $C D$ of poly(S-benzyl D- and L-penicillamines) in a $95-\%$ chloroform-5-\% TFA mixture at $22^{\circ} \mathrm{C}$.

handed one.

The ORD and the CD curves in a chloroform-TFA $(95: 5)$ mixture are shown in Figures 9 and 10. In this solvent system, the behaviors of both D- and L-polymers differ greatly from the results shown in Figures 6 and 7. The absorbency of the side chain shows a sudden reversal. Poly( $S$-benzyl D-penicillamine) has a negative trough at $252 \mathrm{~nm}$ and L-polymer has a positive one. The D-polymer exhibits two negative Cotton effects at 272 and $263 \mathrm{~nm}$ due to the side chain, a trough at $252 \mathrm{~nm}$ with

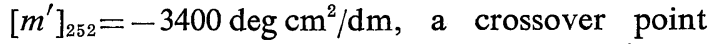
at $242 \mathrm{~nm}$, a shoulder at $230 \mathrm{~nm}$ with $\left[\mathrm{m}^{\prime}\right]_{230}=$ $+4000 \mathrm{deg} \mathrm{cm}^{2} / \mathrm{dm}$, and a peak at $219 \mathrm{~nm}$ with $\left[\mathrm{m}^{\prime}\right]_{219}=+20000 \mathrm{deg} \mathrm{cm} / \mathrm{dm}$. As shown in Figure 10, the CD curves correspond well to the ORD curves and exhibit two negative dichroism bands at 242 and $224 \mathrm{~nm}$ with $[\theta]_{242}=$ -6400 and $[\theta]_{224}=-10000$, in the D-polymer. The L-polymer yielded an almost identical curve with an opposite sign. In a chloroform-TFA (95:5) mixture the $\mathrm{D}$ - and L-polymers have a reverse-type polypeptide conformation from that in 100-\% chloroform. Comparing the conformation in a chloroform-TFA mixture with that in $100-\%$ chloroform, the $n-\pi^{*}$ peptide transition is found in the same position and has 
the same sign and a larger magnitude. However, the $\pi-\pi^{*}$ transition due to the benzyl group has the opposite sign showing a change in the secondary structure.

Infrared Spectra of Poly(S-benzyl D-penicillamine) in Solution. In order to determine the secondary structure in a chloroform-TFA mixture, IR solution measurements were carried out. The results are shown in Figure 11. In $100-\%$ chloroform the amide I band at 1660 $\mathrm{cm}^{-1}$ shows the $\omega$-structure and in a chloroformTFA $(97: 3)$ mixture the amide I at $1625 \mathrm{~cm}^{-1}$ shows the $\beta$-structure. The latter is very close to the conformation of poly(L-cysteine) deriva-

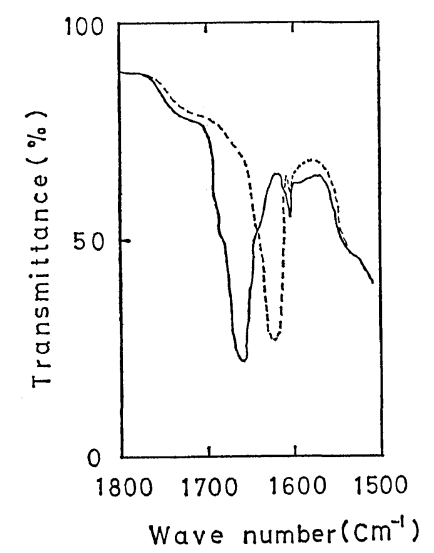

Figure 11. Infrared spectra of $\operatorname{poly}(S$-benzyl Dpenicillamine) in solution at $22^{\circ} \mathrm{C}:(-)$ in chloroform; (----) in 97-\% chloroform-3-\% TFA.

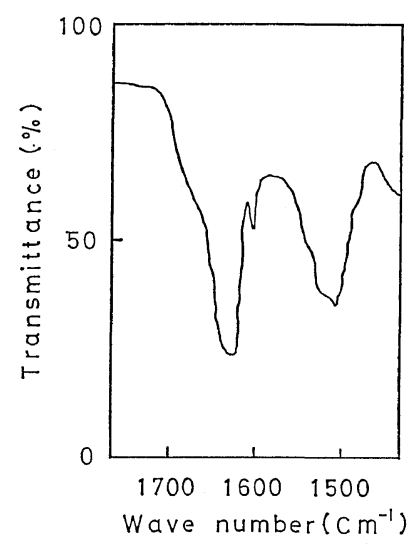

Figure 12. Infrared spectrum of $\operatorname{poly}(S$-benzyl Dpenicillamine) which was precipitated by the addition of excess TFA (KBr disk). tives in solution. ${ }^{1}$

Poly( $S$-benzyl D- and L-penicillamines) are soluble in a chloroform-TFA mixture containing up to 20-\% TFA. The white polymer precipitates at TFA percentages greater than 20. The polymer was precipitated by the excess addition of TFA, washed with ether, and dried. The IR spectrum of the $\operatorname{poly}(S$-benzyl Dpenicillamine) thus prepared is shown in Figure 12. This shows the absorptions at 1625 and $1520 \mathrm{~cm}^{-1}$, and suggests the polymer has the $\beta$ structure. X-ray photograph of this sample shows a backbone spacing of about $4.6 \AA$ ( $\beta$ structure) and coincides well with the results of the IR spectrum.

Intrinsic Viscosity and Flotation Coefficient of Poly(S-benzyl D-penicillamine) in Solution. To elucidate the $\beta$-structure in a chloroform-TFA mixture, intrinsic viscosity, $[\eta]$, and flotation coefficient, $S_{\mathrm{f}}$, measurements were carried out. Figure 13 shows the viscosity of poly( $S$-benzyl D-penicillamine) in solution. The plot gave a straight line in chloroform, and the ordinate intercept, [ $\eta$ ], is $0.265 \mathrm{~d} l / g$. In a chloroformTFA $(95: 5)$ mixture it gave a smooth curve at low concentration (within $0.8 \mathrm{~g} / \mathrm{d} l$ ) and $[\eta]$ is about $0.420 \mathrm{~d} l / g$. In comparison with the former, the $[\eta]$ value is much larger. By combining the magnitude of $[\eta]$ with the marked increase in the reduced viscosity at higher

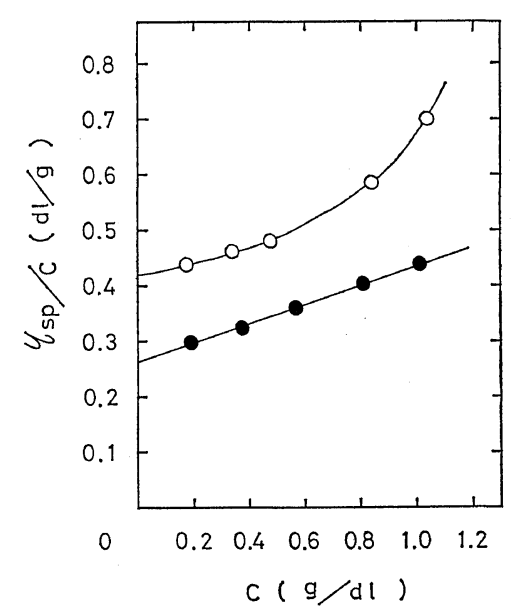

Figure 13. The reduced viscosities of $\operatorname{poly}(S$-benzyl D-penicillamine) in solutions at $20^{\circ} \mathrm{C}:(0)$ in chloroform; $(\bigcirc)$ in a $95-\%$ chloroform-5-\% TFA. 
concentration (above $0.8 \mathrm{~g} / \mathrm{d} l$ ), it is suggested that the polymer exists in an intermolecular $\beta$ structure. Further, the same behavior was observed in the measurement of the flotation coefficient, $S_{\mathrm{f}}$, in solution. The $S_{\mathrm{f}}$ value is 1.28 (sbedberg unit) in chloroform and 2.56 in a chloroform-TFA $(95: 5)$ mixture for a polymer concentration of $0.510 \mathrm{~g} / \mathrm{d} l$ at $22^{\circ} \mathrm{C}$. This result shows that the conformation of the polymer in a chloroform-TFA mixture is the same as the viscometry and supports the formation of an intermolecular $\beta$-structure.

As described above, the ORD, CD, IR, viscometry, and flotation results suggest that poly( $S$-benzyl D- and L-penicillamines) in chloroform take the $\omega$-helical conformation, and their screw senses are reversed for the usual polypeptides. Both D- and L-polymers take the intermolecular $\beta$-structure in a chloroform-TFA mixture. These polymers cause an $\omega$-helical conformation $\rightleftharpoons \beta$-structure transition, which differs from the usual $\alpha$-helix $\rightleftharpoons$ coil or $\beta$-structure $\rightleftharpoons$ coil transitions. We propose here an assumption that a polypeptide with branching on the $\beta$-carbon in its side chain causes an $\omega \rightleftharpoons \beta$ transition owing to the steric hindrance between the side chain and main chain.

Acknowledgment. The authors wish to express their thanks to Professor J.T. Yang of the University of California for reading this manuscript and for offering valuable suggestions and comments.

\section{REFERENCES}

1. K. Kamashima, J. Phys. Soc. Japan, 21, 1781 (1966).

2. B. S. Harrap and I. W. Stapleton, Biochim. Biophys. Acta, 75, 31 (1963).

3. S. Ikeda, H. Maeda, and T. Isemura, J. Mol. Biol., 10, 223 (1964).

4. E. V. Anufrieva, I. A. Bolotina, B. Z. Volchek,
N. G. Illarionova, V. I. Kalikhevich, O.Z. Korotkina, Yu. V. Mitin, O. B. Ptitsyn, A. V. Purkina, and V.E. Eskin, Biofizika, 10, 918 (1965).

5. E. R. Blout in "Polyamino acids, Polypeptides, and Proteines," M. A. Stahmann, Ed., University of Wisconsin Press, Wisconsin, 1962, p 275.

6. H.M. Crooks, The Chemistry of Penicillin, Princeton University Press, Princeton, N.J., 1949, p 452; L. H. Werner, A. Wettstein, and K. Miescher, Helv. Chim. Acta, 30, 432 (1947).

7. T. Miyazawa and E. R. Blout, J. Amer. Chem. Soc., 83, 712 (1961).

8. C. H. Bamford, A. Elliott, and W. E. Hanby, Synthetic Polypeptides, Academic Press, New York, N.Y., 1956, p. 263; Y. Mitsui, Y. Iitaka, and M. Tsuboi, J. Mol. Biol., 24, 15 (1967).

9. R. D. B. Fraser, T. P. Mac Rae, and I. W. Stapleton, Nature, 193, 573 (1962).

10. E. M. Bradbury, L. Brown, A. R. Downie, A. Elliott, R. D. B. Fraser, and W. E. Hanby, $J$. Mol. Biol., 5, 230 (1962).

11. J. P. Baldwin, E. M. Bradbury, I. F. McLuckie and R.M. Stephens, Macromolecules, 6, 83 (1973).

12. E. R. Blout, C. de Lozé, S. M. Bloom, and G. D. Fasman, J. Amer. Chem. Soc., 82, 3787 (1960).

13. R. D. B. Fraser, B. S. Harrap, T. P. Mac Rae, F. H. C. Stewart, and E. Suzuki, J. Mol. Biol., 14, 423 (1965).

14. G. D. Fasman in "Polyamino acids, polypeptides, and Proteins," M. A. Stahmann, Ed., University of Wisconsin Press, Wisconsin, 1962, p 221.

15. M. Goodman, C. M. Deber, and A. M. Felix, J. Amer. Chem. Soc., 84, 3773 (1962).

16. M. Goodman, A. M. Felix, C. M. Deber, A. R. Branse, and G. Schwartz, Biopolymers, 1, 371 (1963).

17. D. F. Bradley, M. Goodman, A. M. Felix, and R. Records, ibid., 4, 607 (1966).

18. M. Goodman and E. Peggion, Biochemistry, 6, 1533 (1967).

19. T. Hayakawa, Y. Kondo, and H. Yamamoto, Bull. Chem. Soc. Japan, 42, 1937 (1969). 